\title{
PATHOGENESIS OF THE JARISCH-HERXHEIMER REACTION
}

A REVIEW OF CLINICAL AND EXPERIMENTAL OBSERVATIONS*

\author{
BY \\ ALBERT HEYMAN, WALTER H. SHELDON, and LILIAN D. EVANS \\ From the Departments of Medicine and Pathology, Emory University School of Medicine, and \\ Grady Memorial Hospital, Atlanta, Georgia, U.S.A.
}

During the past few years we have been engaged in a clinical and experimental study of the pathogenesis of the Jarisch-Herxheimer reaction in syphilis. The results of this investigation have been published in a series of papers (Sheldon and Heyman, 1949 ; Sheldon, Heyman, and Evans, 1951a, b, 1952). The present report summarizes our observations and presents our concepts of the pathogenesis of the Herxheimer reaction in syphilis, as well as in other infections. We shall use this opportunity to speculate upon the significance of the reaction as a manifestation of a hypersensitivity phenomenon.

The Herxheimer reaction has long been known to be a common occurrence in the treatment of syphilis, but its pathogenesis has evoked little interest. The reaction is generally attributed to the release of endotoxins or spirochaetal breakdown substances following the initial administration of spirochaeticidal agents. These substances are thought to produce systemic manifestations, such as fever, chills, and malaise, as well as an exacerbation of syphilitic lesions. The results of our studies seem to indicate that the Herxheimer reaction is a hypersensitivity phenomenon of the delayed type similar to the focal hypersensitivity type of tuberculin reaction.

\section{Occurrence of Herxheimer-like Reactions in Various Diseases}

Herxheimer reactions occur not only in syphilis, but also in other spirochaetal infections, such as yaws (Dwindelle and others, 1946), Vincent's infection (Williams, 1941), and relapsing fever (Wolff, 1946). Recent reports indicate that the reaction may also appear in leptospiral diseases (Suchett-Kaye, 1951). It has been frequently

* Address delivered by Dr. Heyman to the Medical Society for the Study of Venereal Diseases, September 28, 1951.

This study was aided by a grant from the National Institutes of Health United States Public Health Service. observed in rat-bite fever caused by Spirillum minus (Brown and Nunemaker, 1942). The recognition of Herxheimer reactions in this group of infections can probably be attributed to the use of organic arsenicals, which were the first effective chemotherapeutic compounds. The development of new chemotherapeutic agents and antibiotics, however, has led to the recognition of Herxheimer reactions in a variety of other infections. The methods currently employed in the treatment of brucellosis frequently produce intensification of signs and symptoms of the disease with transient episodes of chills and fever. These reactions occur in 25 to 50 per cent. of patients with brucellosis and follow the use of aureomycin, chloramphenicol, terramycin, or combined sulphonamide-streptomycin therapy (Knight, 1950). The appearance of the reaction within a few hours after therapy suggests that the reaction is probably caused by destruction of the causative organism. Similar Herxheimer-like reactions have been described in patients with glanders (Womack and Wells, 1949) and tularaemia (Foshay, 1947) treated with streptomycin. Mention has also been made recently of an exacerbation of symptoms in leprosy treated with diasone (Faget and Erickson, 1948), and in anthrax treated with aureomycin (Gold, 1950).

The Herxheimer reaction in syphilis is thought to be similar in many respects to the systemic type of tuberculin reaction, but there has been, to our knowledge, no evidence that patients with tuberculosis treated with either streptomycin or paraaminosalicylic acid show an intensification of signs or symptoms similar to the Herxheimer reaction. We have observed a few instances of transient fever during the first few hours of streptomycin therapy in patients with tuberculosis, but no definite conclusions could be drawn regarding its significance. Efforts to produce morphological or other evidence of the Herxheimer reaction in tuberculous guinea- 
pigs treated with streptomycin have been unsuccessful. Tissue removed from the draining sinus of one patient with tuberculous lymphadenitis before and after the beginning of treatment with streptomycin showed morphological changes similar to those observed in the lesions of syphilis during the Herxheimer reaction. We have had no opportunity of repeating this experiment.

\section{Herxheimer Reaction in Various Stages of Syphilis}

Early Syphilis.-The Herxheimer reaction is thought to occur in approximately 40 per cent. of patients with early syphilis (Farmer, 1948). The actual incidence, however, depends on the criteria determining the presence of the phenomenon, the therapeutic agent used, and, perhaps, the type and severity of the syphilitic lesions. The reaction usually consists of a single episode appearing within the first few hours of the institution of therapy. Multiple reactions have been observed, however, in patients given initially small but subsequently increasing doses of arsenicals or penicillin. Evidence of Herxheimer reactions in cutaneous and mucosal lesions may be observed for several days in patients receiving repository preparations of penicillin.

The possibility that the Herxheimer reaction might be the result of a release of histamine or similar substances suggested to us the use of antihistaminic compounds, together with penicillin. The reaction occurred in patients with early syphilis receiving either pyribenzamine or benadryl as often as in patients receiving antisyphilitic therapy alone (Stewart, 1949 ; Heyman and Sheldon, 1948). Attempts to find histamine-like substances in the serum of patients during the Herxheimer reaction gave negative results (Morrison, Heyman, and Sheldon, 1948).

Neurosyphilis.-The use of penicillin in the treatment of neurosyphilis produced more frequent and severe Herxheimer reactions than were observed following arsenical therapy. The frequency of the reaction in patients with symptomatic neurosyphilis treated with penicillin in this clinic is shown in the Table. These patients were afebrile at the beginning of therapy and received penicillin alone

TABLE

HERXHEIMER REACTIONS IN NEUROSYPHILIS FOLLOWING PENICILLIN THERAPY

\begin{tabular}{l|c|c|c|c}
\hline \multirow{2}{*}{ Diagnosis } & \multirow{2}{*}{$\begin{array}{c}\text { No. } \\
\text { Patients }\end{array}$} & \multicolumn{3}{|c}{ Herxheimer Reaction } \\
\cline { 4 - 6 } & & Symptomatic & Fever Only & Total \\
\hline Paresis &. & 64 & 17 & 23 \\
Tabes & 8 & 1 & 1 & 2 \\
Meningomyelitis & 19 & 2 & 2 & 4 \\
\hline
\end{tabular}

in dosages varying from 1,000 to 50,000 units. During the first 24-36 hours after penicillin therapy, 23 ( 52 per cent.) of the 44 patients with paresis showed a definite febrile reaction with a rise of temperature to $100^{\circ} \mathrm{F}$. or more. Six of these 23 patients also showed a transient intensification of their psychotic manifestations. Of eight patients with tabes, two had evidence of a febrile reaction, one of whom also showed an increase in lightning pains. Two patients with meningomyelitis developed more severe spinal cord manifestations which may have been the result of a Herxheimer reaction (Jones, Heyman, Smith, and Wilson, 1951).

It has been estimated that approximately 64 to 79 per cent. of all patients with neurosyphilis treated with penicillin develop Herxheimer reactions (Hoekenga and Farmer, 1948). The incidence is particularly high in paresis and seems to be more common in patients with markedly abnormal spinal fluid findings. The reactions in neurosyphilis usually consist of elevation of temperature, but occasionally irreversible damage develops. Death has been reported after penicillin therapy in a patient with cerebral gumma (Scott, Maxwell, and Skinner, 1949), and in another with syphilitic pachymeningitis (Shaffer and Shenkin, 1950). Histological study of the nervous system of these patients revealed changes in the syphilitic lesions resembling those occurring in early syphilis during the Herxheimer reaction. We had an opportunity of examining histological preparations of the gumma mentioned above.* The lesion showed marked congestion, acute inflammation, and oedema, findings usually absent in patients with uncomplicated gummatous lesions. There is little doubt that the Herxheimer reaction was an important factor in the death of these patients.

The changes in cerebral circulation and metabolism caused by the Herxheimer reaction were studied in a few patients with neurosyphilis (Heyman, Patterson, Nichols, and Jones, 1951). This investigation was carried out with the use of the nitrous oxide technique in six patients with paresis and in one with meningovascular syphilis. Only as light increase in the mean cerebral blood flow of these patients was observed. Two of the patients with clinical evidence of a Herxheimer reaction showed a fall in cerebral metabolism. We are not certain of the significance of these findings because of the small number of patients studied. The expected increase in the cerebral circulation may have been prevented by the marked oedema of the tissues which appears during the Herxheimer reaction.

\footnotetext{
* We are indebted to Dr. Virgil Scott, St. Louis, Mo, for sending
} us the sections of this case. 
Cardiovascular Syphilis. - The danger of a serious Herxheimer reaction in cardiovascular syphilis after penicillin therapy is thought to have been greatly exaggerated and is now believed to be of little significance (Moore, 1949 ; Sinclaire and Webster, 1951). Detailed information regarding the frequency of febrile Herxheimer reactions in patients with cardiovascular syphilis and co-existent nervous system involvement is given in several reports (Tucker and Farmer, 1947 ; Sinclaire and Webster, 1951 ; Wheeler and Curtis, 1951 ; Coale, Allen, and Delp, 1950). Only fourteen of 155 patients with either aortic insufficiency or aneurysm developed febrile reactions after penicillin-an incidence

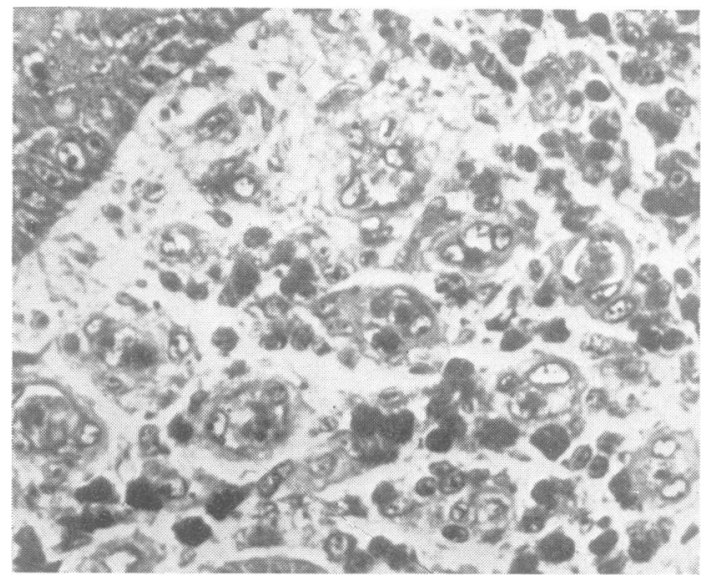

(a) Before treatment. Connective tissue beneath epithelium (left upper corner) shows chronic inflammation with a few small blood vessels.

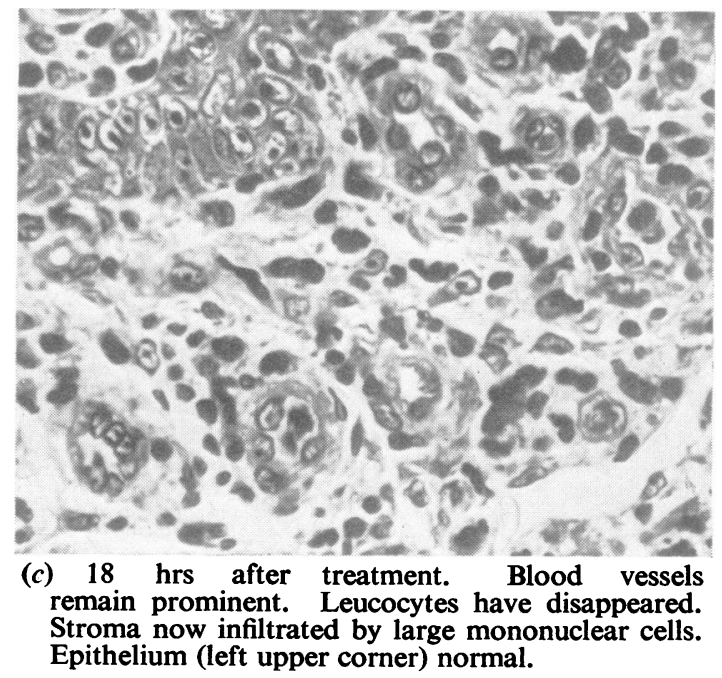

FIG. 1.-Condylomatous lesion. considerably less than that occurring in early syphilis or neurosyphilis. Moreover, thirteen of the fourteen patients with Herxheimer reactions had evidence of neurosyphilis. This suggests that the reaction might be related to the co-existing neurosyphilis rather than to the cardiovascular syphilis alone. The development of angina pectoris, increased congestive failure, or rupture of an aortic aneurysm have been attributed to the effects of penicillin therapy (Scott, Maxwell, and Skinner, 1949 ; Dolkart and Schwemlein, 1945 ; Porter, 1948 ; Callaway and others, 1946), but there is no clear-cut evidence that these manifestations were related to a Herxheimer reaction.

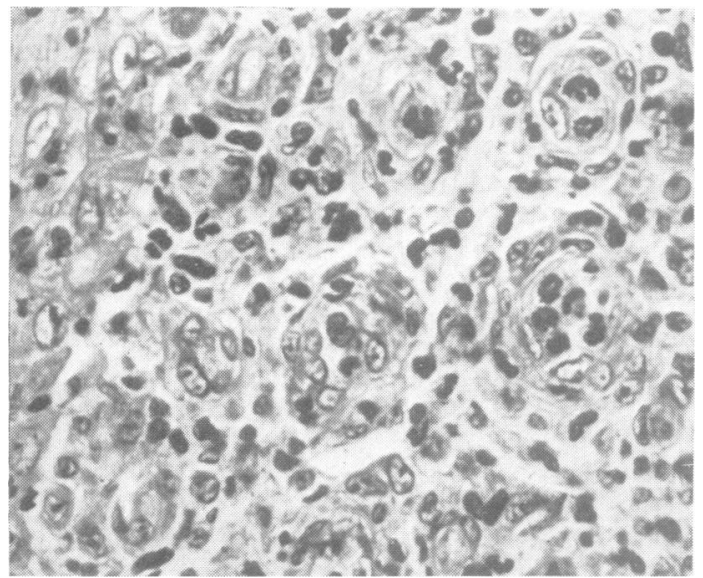

(b) 6 hrs. after treatment. Blood vessels now prominent and crowded with leucocytes, which infiltrate vessel walls and oedematous connective tissue. The epithelium (left) is also oedematous.

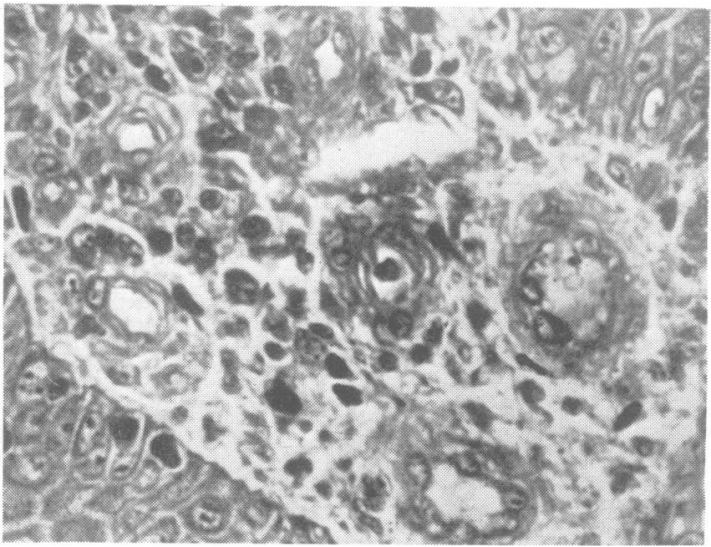

(d) $72 \mathrm{hrs}$ after treatment. Acute inflammatory changes have subsided and the picture is similar to that before treatment (Fig. 1a).

Phloxine-methylene blue $\times 530$. 
Despite the lack of a well-authenticated instance of a serious Herxheimer reaction in cardiovascular syphilis, we believe that such reactions are possible. This opinion is based upon the study of a patient in this hospital with gummatous aortitis who died a few hours after an initial administration of penicillin (Whorton and Denham, 1951). At autopsy, the aortic lesions showed the acute inflammatory changes associated with the Herxheimer reaction. The death of this patient was not directly related to cardiovascular syphilis and was probably caused by pulmonary embolism. Gummatous aortitis is relatively uncommon and constitutes less than 3 per cent. of patients with syphilitic aortitis (Gordon, Parker, and Weiss, 1942). As yet, there are no reports regarding histological evidence of a Herxheimer reaction in patients with non-gummatous syphilitic aortitis. Serious Herxheimer reactions are therefore not of practical importance in the management of cardiovascular syphilis.

\section{Morphological Changes in Syphilitic Lesions during the Herxheimer Reaction}

We have made numerous histological studies of syphilitic lesions in both patients and experimental animals during the Herxheimer reaction (Sheldon and Heyman, 1949). At the beginning of each experiment, lesions similar in size and appearance were selected and one was excised before the initiation of specific therapy. The other lesions were removed at varying intervals after therapy. Histological changes consisting of transient acute inflammation were observed in the syphilitic lesions 4 to 6 hours after the beginning of treatment. At first, the capillaries and small blood vessels (chiefly veins) became congested. They later became crowded with neutrophilic polymorphonuclear leucocytes, the vascular endothelium swelled, and the leucocytes migrated through the vessel wall into the surrounding tissues which were oedematous. The acute process subsided after 14 to 18 hours, at which time the oedema disappeared and large mononuclear cells replaced the polymorphonuclear leucocytes. The changes were no longer present 72 hours after initiation of therapy (Figs 1 and 2).

These changes were encountered in practically every patient with clinical evidence of a Herxheimer reaction. They do not occur in the natural course of syphilitic infection, but are observed only after specific therapy. In our experience, the histological changes were a more sensitive criterion of the presence of the Herxheimer reaction than either elevation of temperature, leucocytosis, or the development of local or systemic manifestations.

FIg. 2.-Condylomatous lesion. Phloxine-methylene blue $\times 690$.

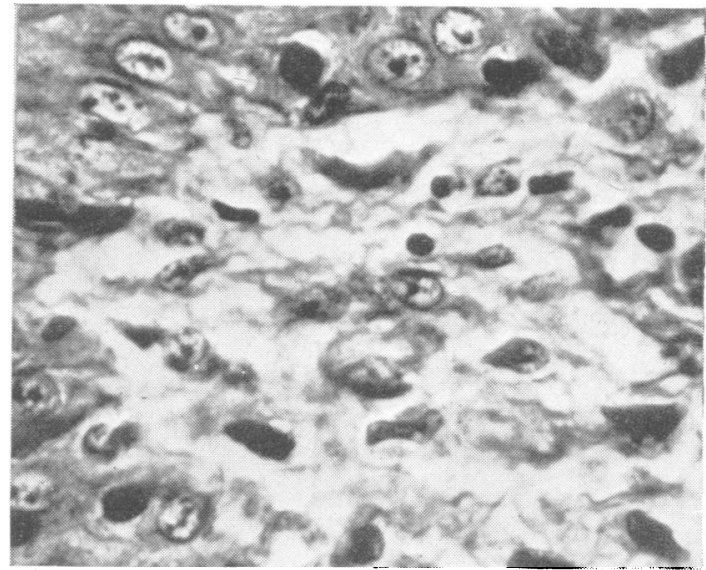

(a) Before treatment. Connective tissue beneath epithelium (left) shows slight chronic inflammation. Capillaries not visible.
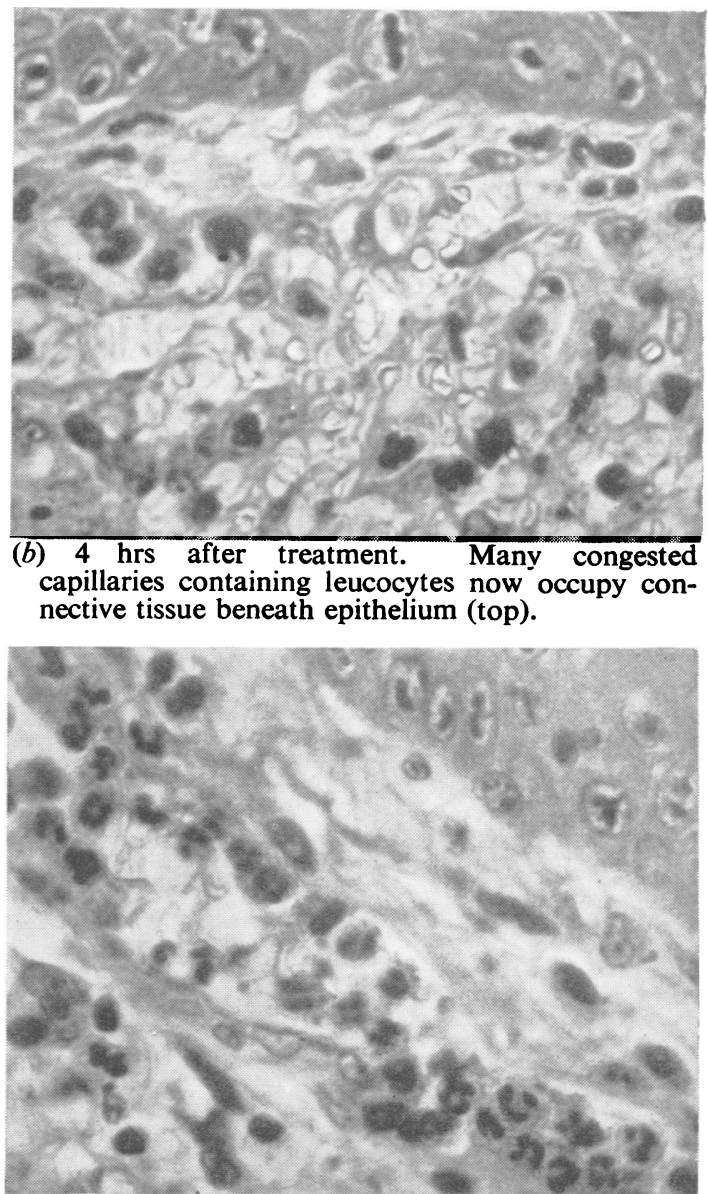

(c) $7 \mathrm{hrs}$ after treatment. A small vein beneath the epithelium (right upper corner) is crowded with leucocytes which have begun to infiltrate the oedematous connective tissue. 


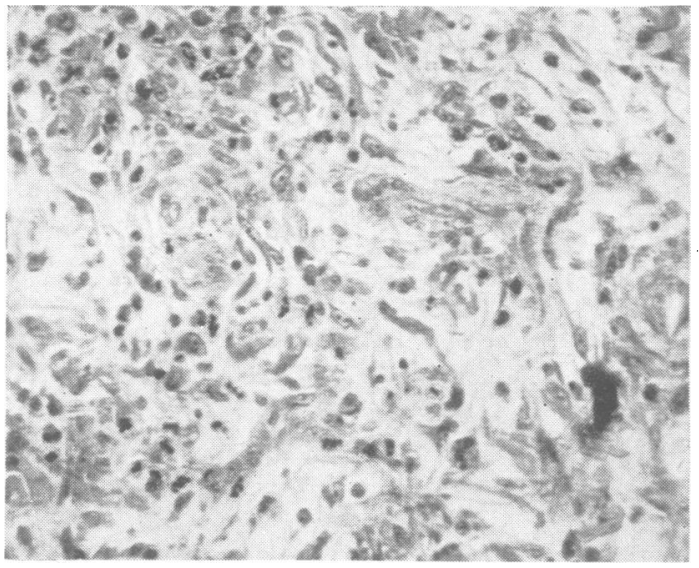

(a) Lesion excised before injection of penicillin. Polymorphonuclear leucocytes are sparse among the inflammatory-cell infiltrate.

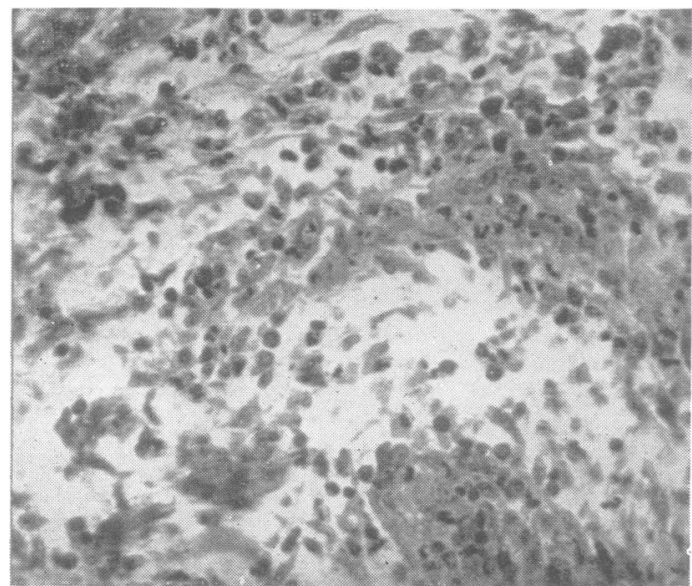

(b) Excised 4 hrs after initial penicillin treatment, polymorphonuclear leucocytes now a prominent part of inflammatory process.

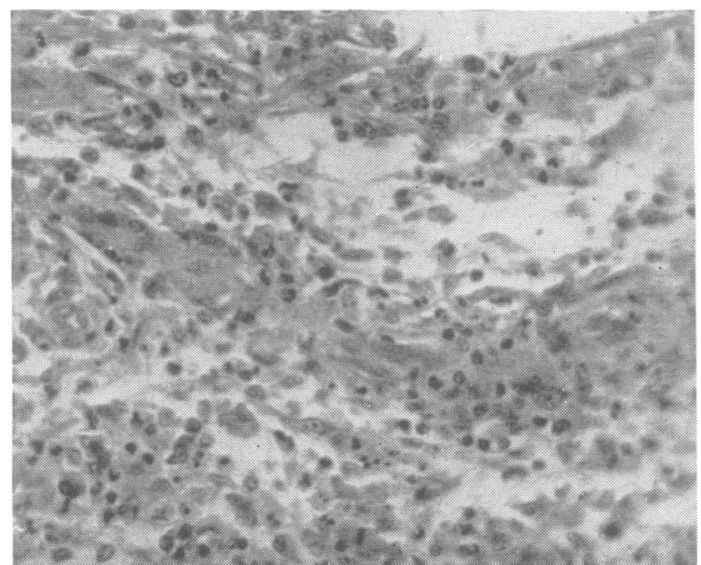

(c) Excised $8 \mathrm{hrs}$ after treatment. Leucocytes numerous.

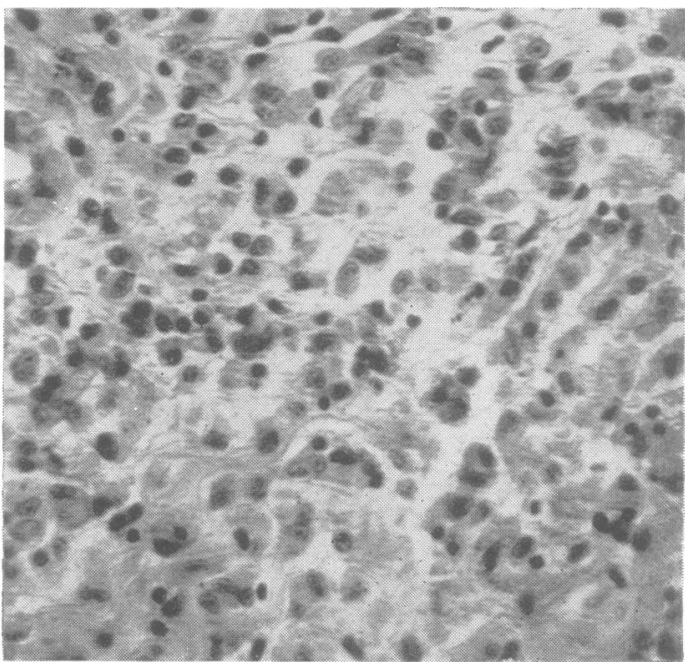

(a) Excised before penicillin treatment. No polymorphonuclear leucocytes among inflammatory cells.

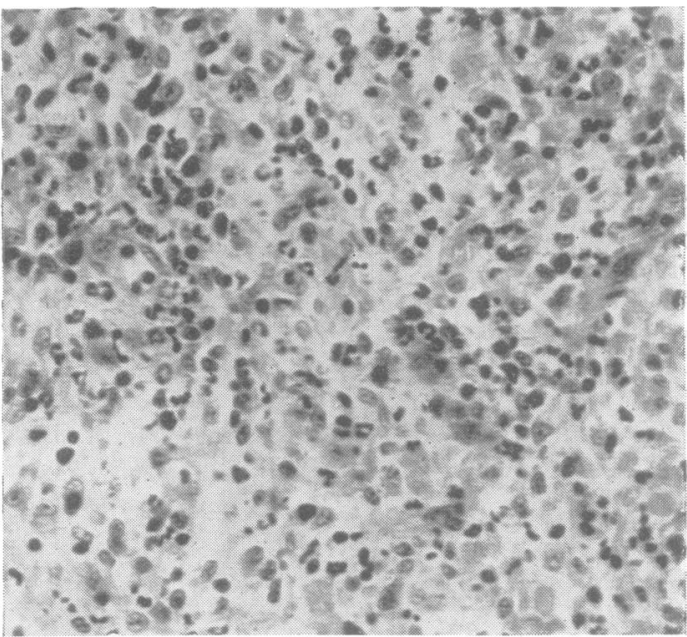

(b) Excised $7 \mathrm{hrs}$ after administration of penicillin. Many polymorphonuclear leucocytes.

FIG. 4.-Skin lesion of rabbit infected with $S$. minus. Phloxine-methylene blue $\times 480$.

\section{Herxheimer Reactions in Laboratory Animals}

Histological changes similar to those observed in human syphilitic lesions were produced in rabbits with experimental syphilis by the administration of penicillin or arsenoxide (Fig. 3).

We made numerous attempts to elicit these changes by the injection of living and dead Treponema pallidum. Before injection, the treponemata were treated in various ways in an attempt to release antigenic substances. The procedures included heating, repeated freezing and thawing, 


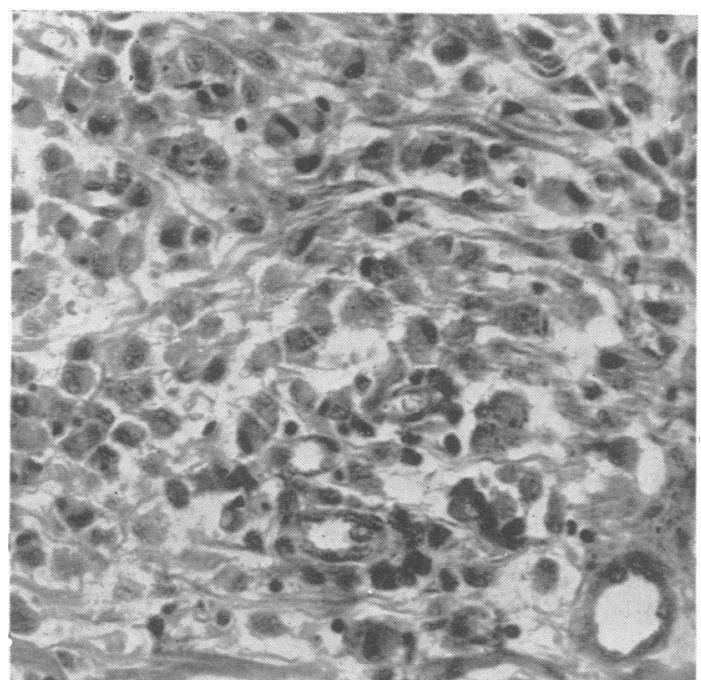

(a) Excised before injection of specific immune serum. Polymorphonuclear leucocytes not part of inflammatory reaction.

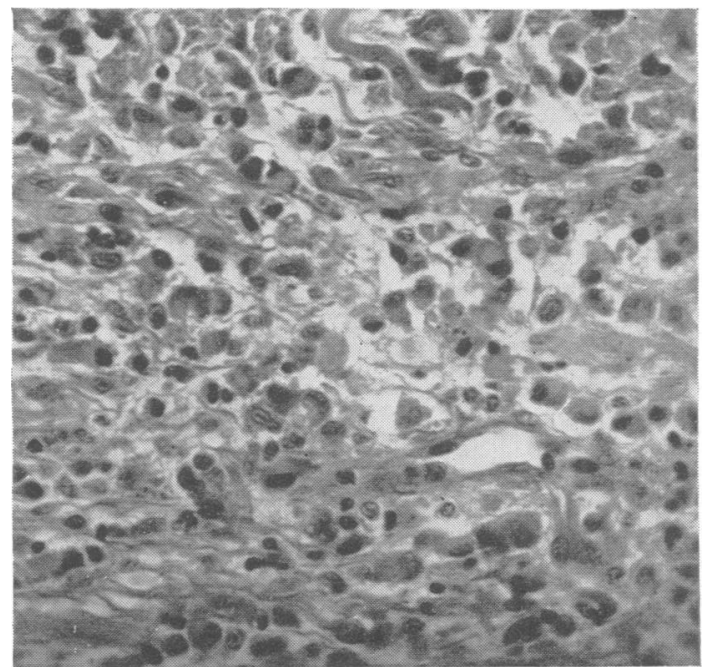

(c) Excised before injection of normal serum.

FIG. 5.-Skin lesion of rabbit infected with exposure to spirochaeticidal drugs and incubation with immune serum, but the results of these experiments were inconclusive. Attempts to demonstrate treponemal toxins by intravenous and intracerebral injection of living and dead spirochaetes into young mice also produced no results.

Since Herxheimer reactions are known to occur in patients with Spirillum minus infections following spirillicidal therapy, we began a study of this infection in laboratory animals (Sheldon, Heyman, and Evans, 1951a). Biopsies of the cutaneous

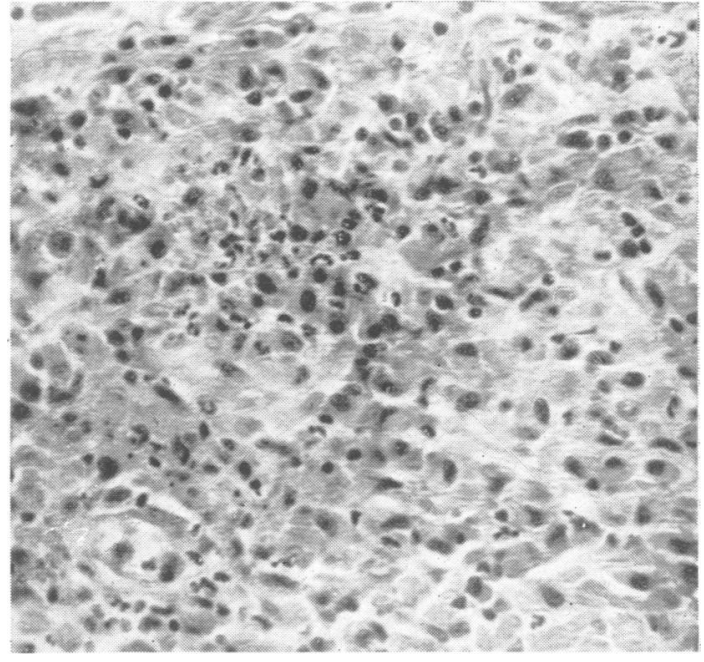

(b) Excised 8 hrs after injection of specific immune serum. Note distinct infiltration with polymorphonuclear leucocytes.

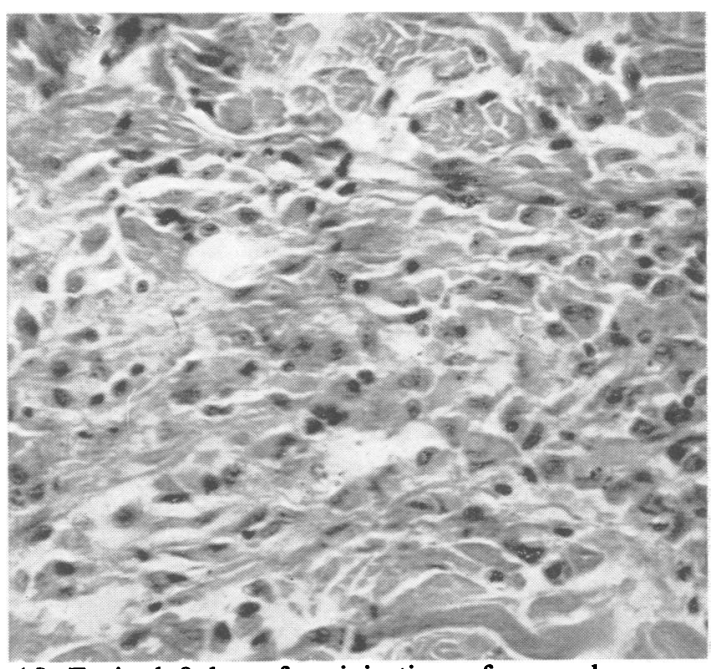

(d) Excised $8 \mathrm{hrs}$ after injection of normal serum. No appreciable difference between $(c)$ and $(d)$.

$S$. minus. Phloxine-methylene blue $\times 480$.

lesions of rabbits infected with $S$. minus were taken before and at 2-hour intervals more treatment with penicillin (Fig. 4). Changes very similar to those observed in syphilitic lesions of rabbits following penicillin therapy were found in the skin lesions of the Spirillum-infected animals. These changes consisted of a transient, acute inflammatory reaction with infiltration of polymorphonuclear leucocytes, oedema and congestion. The reaction appeared within 4 hours and reached its peak within 6 to 8 hours. 


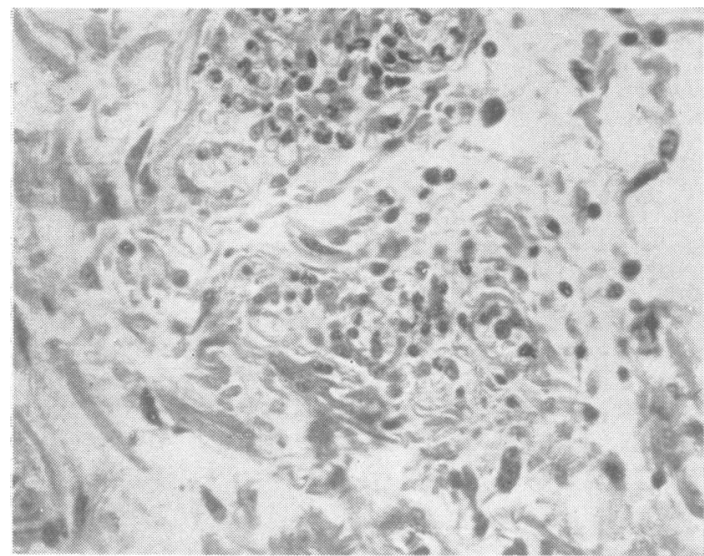

(a) Lesion excised before injection of serum.

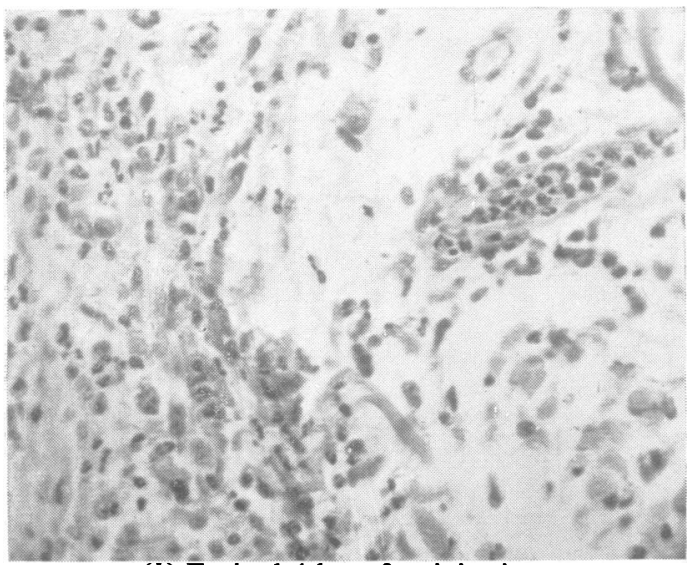

(b) Excised $4 \mathrm{hrs}$ after injection.

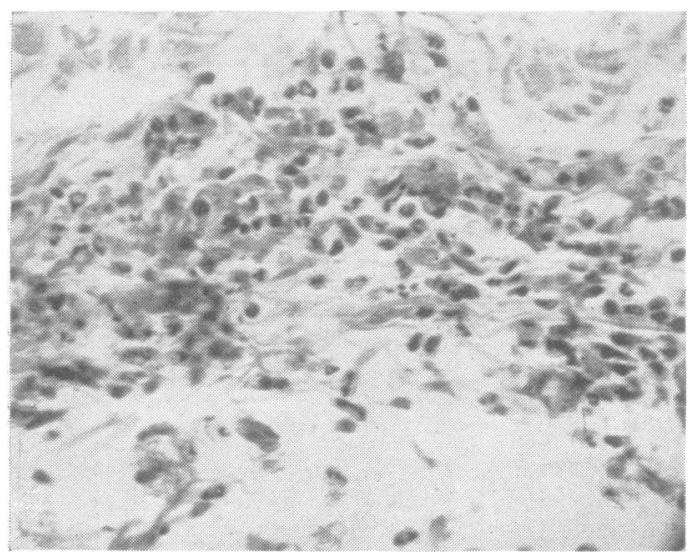

(c) Excised 8 hrs after injection. Note marked diffuse infiltration with polymorphonuclear leucocytes, which in $(b)$ pack a small vessel (right centre).

FIG. 6.-Herxheimer reaction in skin syphiloma of rabbit after injection of syphilitic serum. Phloxinemethylene blue $\times 480$.
Lysing and immobilizing antibodies against $S$. minus are known to be present in the serum of animals infected with this organism (McDermott, 1928). We found that dilutions of serum (1: 4 or less) of rabbits infected with $S$. minus were capable of rapidly immobilizing and lysing this organism. A single large dose $(70 \mathrm{ml}$.) of serum pooled from rabbits with untreated $S$. minus infection was injected intravenously into rabbits with skin lesions of this disease. The skin lesions excised from the recipient animals following injection of immune serum showed histological changes similar to those observed after administration of penicillin. The lesions of rabbits receiving an equal amount of serum pooled from uninfected animals showed no discernible changes (Fig. 5, previous page).

These observations led us to investigate the effects of administration of syphilitic immune serum in rabbits with experimental syphilitic infection (Sheldon, Heyman, and Evans, 1951b). Serum from rabbits with untreated syphilis of 8 to 10 weeks duration is known to contain immobilizing antibodies for T. pallidum (Nelson and Mayer, 1949). Immune serum $(70 \mathrm{ml}$.) pooled from infected animals was injected intravenously into each of six rabbits with skin syphilomata. Individual syphilomata were excised from the recipient animals before and at 2-hour intervals following injection of the serum. The lesions of 5 of the 6 animals showed histological evidence of a transient acute inflammation similar to that observed in Herxheimer reactions produced by penicillin (Fig. 6). The skin lesions of an equal number of control rabbits, receiving serum pooled from uninfected rabbits, showed no changes (Fig. 7 , opposite). The serum used was bacteriologically sterile and care was taken to avoid contamination by pyrogenic substances.

These experiments suggested that the Herxheimer reaction might be a hypersensitivity phenomenon in which the hosts' tissues reacted with substances released by destruction of $T$. pallidum. The effect of ACTH on the Herxheimer reaction was then studied (Sheldon and others, 1952), as it was then thought to inhibit or suppress the delayed type of hypersensitivity reaction (Long and Favour, 1950). ACTH (in daily doses of $5 \mathrm{mg}$./kg.) was given intramuscularly to rabbits with skin syphilomata. Lesions excised on the third day of administration of ACTH were compared with those removed before the onset of hormone therapy. A marked decrease in the intensity of the inflammatory and reparative processes was evident following the administration of ACTH. The polymorphonuclear leucocytes were reduced in number and the collections of lymphocytes at the periphery of the lesions were 
less extensive. There was no decrease in the number of large mononuclear cells. New formation of fibroblasts and capillaries was diminished, and the central oedematous core of the lesions had largely disappeared. The animals were then given penicillin therapy and other lesions were excised at regular intervals, while ACTH therapy was continued. Histological changes of the Herxheimer reaction were readily visible in these lesions and resembled in every respect the changes developing after penicillin alone (Fig. 8, overleaf). Clearly ACTH does not inhibit the development of the morphological changes of the Herxheimer reaction.

\section{Discussion}

Definite histological changes have been observed in the syphilitic lesions of both patients and experimental animals during the Jarisch-Herxheimer reaction. These changes consist of a nonspecific, transient, acute inflammation and are believed to be the morphological basis for the clinical manifestations of the Herxheimer reaction. The histological picture and the time of appearance of the reaction resemble those occurring in tuberculous lesions following the introduction of large amounts of tuberculoprotein in hypersensitive individuals (Rich, 1944). In experimental syphilis, however, the reaction could not be produced by the administration of spirochaetal antigens.

At present, it appears that the Herxheimer phenomenon in syphilis can be elicited only when spirochaetes are destroyed by administration of either appropriate antibiotics, chemotherapeutic agents or specific immune serum. Such serum has been shown to contain immobilizing antibodies for $T$. pallidum (Nelson and Mayer, 1949), which probably destroy sufficient numbers of treponemata to evoke a Herxheimer reaction. Destruction of the causative organism seems to be an essential factor in the pathogenesis of the reaction. This is further indicated by the demonstration of Herxheimer-like reactions in a variety of nonspirochaetal infections treated with new antibiotic agents.

Destruction of the aetiological agent, however, is not sufficient in itself to explain many of the known factors regarding the Herxheimer phenomenon. If, as Moore, Farmer, and Hoekenga (1948) have pointed out, the reaction were due solely to the release of spirochaetal breakdown substances, its incidence and severity should vary with (1) the number of treponemata present in a given individual at the time of treatment, and (2) the number of organisms destroyed by specific therapy. These workers, however, have observed that the incidence of Herxheimer reactions in patients with sero-

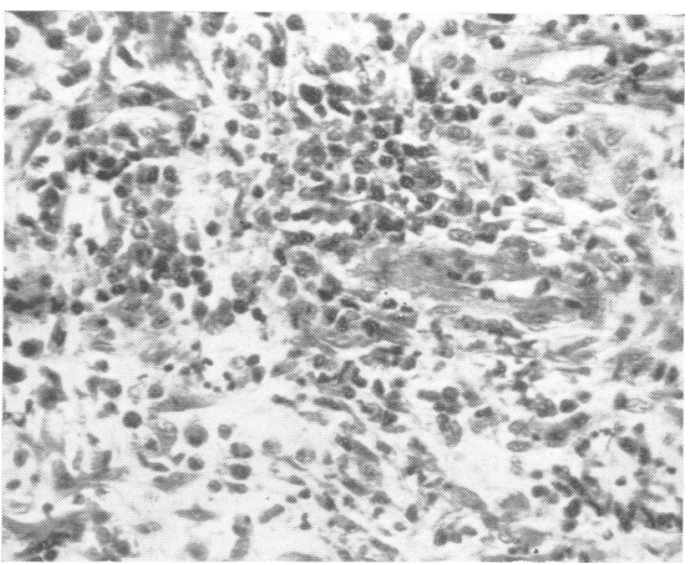

(a) Lesion excised before injection of serum.

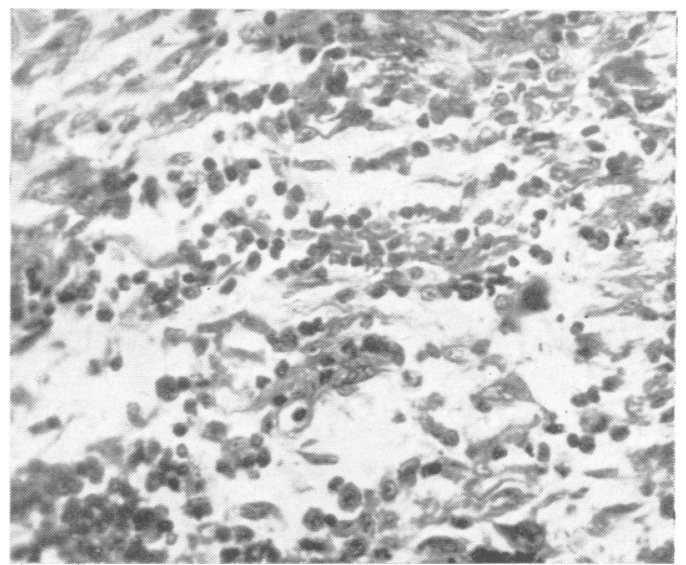

(b) Excised 4 hrs after injection.

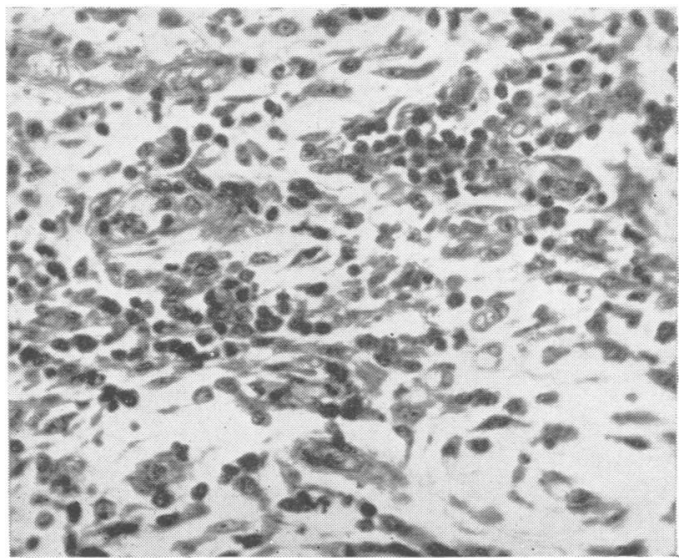

(c) Excised $8 \mathrm{hrs}$ after injection.

Fig. 7.--Injection of normal serum producing no changes in skin syphiloma of rabbit. Phloxinemethylene blue $\times 480$. 


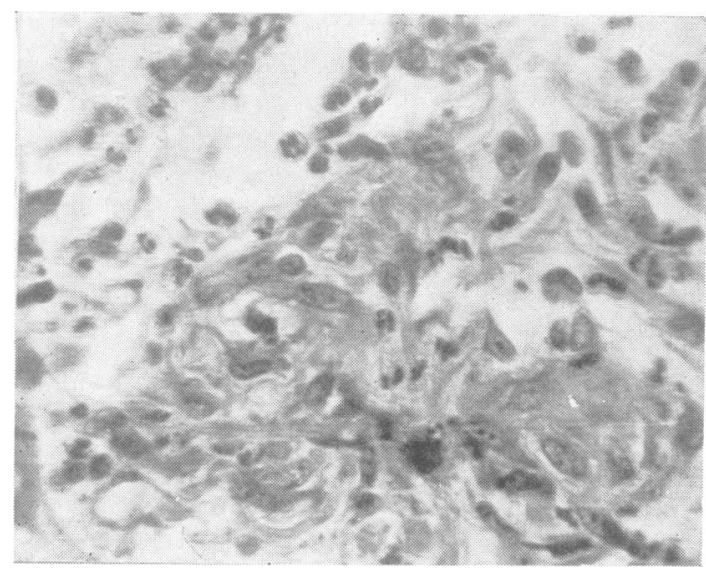

(a) Before administration of ACTH or penicillin.

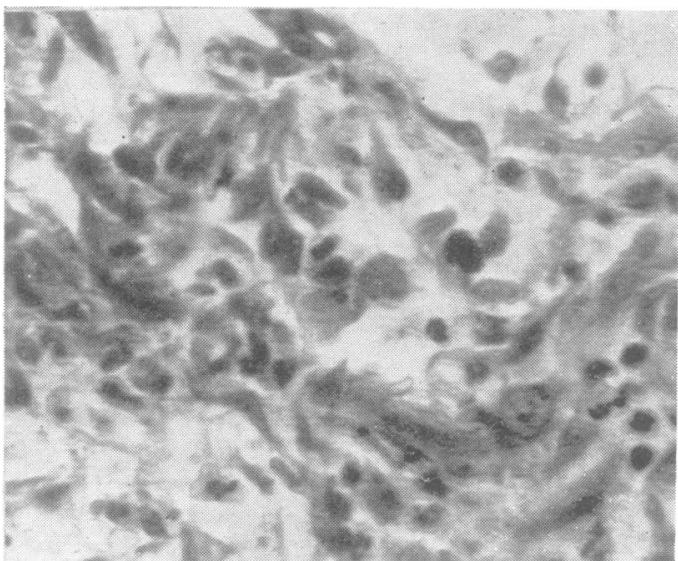

(c) Syphiloma excised 2 hrs after initial injection of penicillin. Appearance of some polymorphonuclear leucocytes.

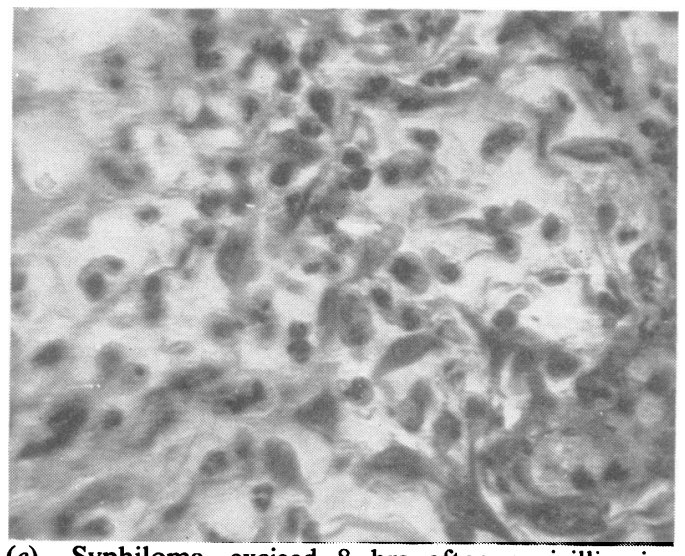

(e) Syphiloma excised $8 \overline{\mathrm{hrs}}$ after penicillin injection. Marked acute inflammatory-cell infiltration.

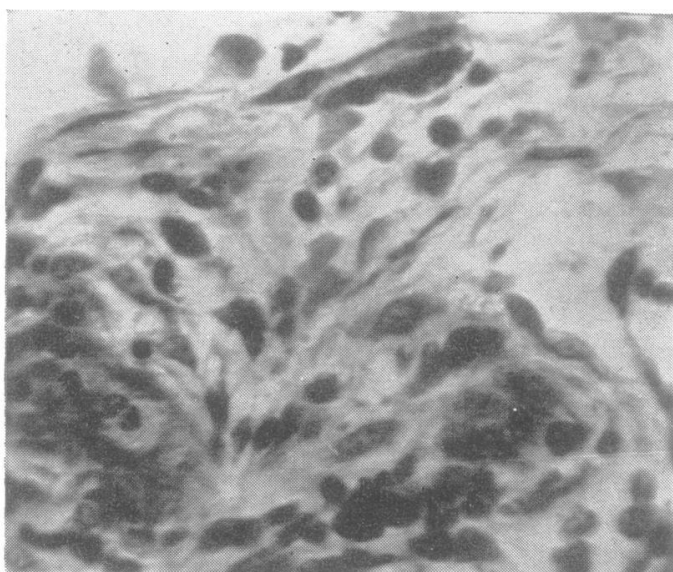

(b) Syphiloma excised on 3rd day of ACTH treatment immediately before injection of penicillin. Decreased cellularity indicates diminished inflammatory-cell infiltration.
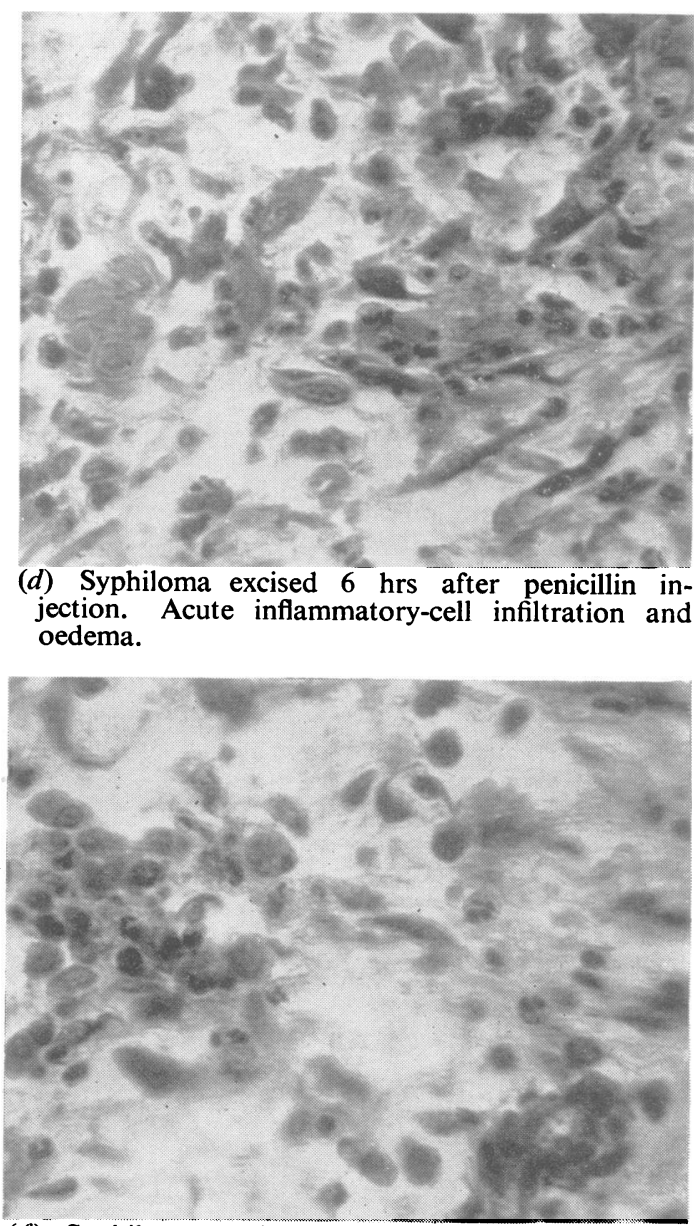

(f) Syphiloma excised $24 \mathrm{hrs}$ after penicillin injection. Subsidence of inflammation.

FIG. 8.-Skin syphiloma of rabbit. Phloxine-methylene blue $\times 660$. 
negative primary syphilis is approximately the same as in patients with secondary syphilis, even though the latter group presumably harbours a greater number of treponemata. Moreover, the reaction occurs in patients with early syphilis who receive penicillin in doses too small to produce any apparent decrease in the number of spirochaetes in cutaneous and mucosal lesions. It is further known that Herxheimer reactions occur in lesions of late syphilis in which spirochaetes are notoriously few.

These apparently conflicting observations can be understood if it can be shown that the Herxheimer reaction is a hypersensitivity phenomenon. In a hypersensitive host the liberation of even minute amounts of antigenic spirochaetal substances could produce a severe systemic reaction. The incidence and severity of the reaction would then be determined primarily by the degree of hypersensitivity rather than the number of organisms. A Herxheimer reaction, therefore, would be produced by any dose of penicillin destroying enough treponemata to release a sufficient quantity of spirochaetal products to act as an antigen.

The failure of ACTH to inhibit the Herxheimer reaction does not conflict with the concept that this phenomenon is a hypersensitivity reaction. It has recently been shown that this hormone does not interfere with the basic immune mechanisms of the delayed type of hypersensitivity (Sheldon, Cummings, and Evans, 1950 ; Derbes and others, 1950). The failure of antihistaminic agents, such as pyribenzamine, to inhibit the Herxheimer reaction suggests that the release of histamine is not a factor in the production of the reaction.

Regarding the role of hypersensitivity in the pathogenesis of the Herxheimer reaction, it is important to point out that hypersensitivity of the tuberculin type is present in all but one (anthrax) of the nonspirochaetal infections in which Herxheimerlike reactions are now being observed. Positive skin reactions of the tuberculin type develop in brucellosis, leprosy, tularemia, and glanders following intradermal inoculation of specific antigens. It appears, therefore, that the existence of the delayed type of hypersensitivity may be an essential factor in the occurrence of the Herxheimer reaction. The lack of suitable antigens, rather than the absence of hypersensitivity, may explain the absence of skin reactions in patients with spirochaetal diseases. It is probable that accurate assessment of the role of hypersensitivity in the pathogenesis of the Herxheimer reaction will be determined only after cultivation of the Treponema pallidum has been achieved and antigenic fractions of the organism have been isolated.
The delayed type of hypersensitivity, manifested by a positive skin reaction to specific antigens, exists in such virus and fungus infections as lymphogranuloma venereum, mumps, coccidioidomycosis, and histoplasmosis. We believe that, as new chemotherapeutic agents are developed for these disorders, Herxheimer reactions will no longer be confined to the spirochaetal diseases, but will be encountered in a variety of infections.

The prevention of the Herxheimer reaction in neurosyphilis is of practical importance. It has been shown that the use of small doses of either penicillin or arsenicals in initiating therapy will not prevent the reaction. Although initial treatment with bismuth over a period of several weeks may prevent a Herxheimer reaction in early syphilis, there is no evidence that such treatment is effective in neurosyphilis. In fact, Sinclaire and Webster (1951) have reported that the use of heavy metals up until the time of penicillin therapy did not prevent Herxheimer reactions in five patients having both cardiovascular and neurosyphilis. Fever therapy has been suggested as a means of preventing the Herxheimer reaction in patients with paresis. This may not be practical, however, since fever therapy itself often produces untoward complications and is thought by many workers to be unnecessary in the treatment of neurosyphilis. It must be concluded that at present there is no practical method for preventing the Herxheimer reaction in patients with neurosyphilis.

\section{Summary}

Clinical and experimental observations on the pathogenesis of the Jarisch-Herxheimer reaction are reviewed. Available evidence indicates that the Herxheimer reaction should be regarded as a hypersensitivity phenomenon of the delayed type.

\section{REFERENCES}

Brown, T. McP., and Nunemaker, J. C. (1942). Bull. Johns Hopk. Hosp., 70, 201.

Callaway, J. L., Noojin, R. O., Flower, A. H., Kuhn, B. H., and Riley, K. A. (1946). Amer. J. Syph., 30, 110.

Coale, L. H., Allen, M. S., and Delp, M. H. (1950). J. Kans. med. Soc., 51, 102.

Derbes, V. J., Dent, J. H., Weaver, N. K., and Vaughan, D. D. (1950). Proc. Soc. exp. Biol., N.Y., 75, 423.

Dolkart, R. E., and Schwemlein, G. X. (1945). J. Amer. med. Ass., 129, 515.

Dwindelle, J. H., Rein, C. R., Sternberg, T. H., and Sheldon, A. J.'(1946). Amer. J. trop. Med., 26, 311. Faget, G. H., and Erickson, P. T. (1948). J. Amer. med. Ass., 136, 451.

Farmer, T. W. (1948). Ibid., 138, 480.

Foshay, L. (1947). Amer. J. Med., 2, 467.

Gold, H. (1950). Ibid., 8, 31. 
Gordon, W. H., Parker, F., and Weiss, S. (1942). Arch. intern. Med., 70, 396.

Heyman, A., Patterson, J. L., Nichols, F. T., and Jones, R. W. (1951). Amer. J. Syph., 35, 301. , and Sheldon, W. H. (1948). Unpublished data.

Hoekenga, M. T., and Farmer, T. W. (1948). Arch. intern. Med., 82, 611.

Jones, R. W., Heyman, A., Smith, W. A., and Wilson, R. (1951). Amer. J. Syph., 35, 72.

Knight, V. (1950). Ann. N. Y. Acad. Sci., 53, Art. 2, p. 332.

Long, J. B., and Favour, C. B. (1950). Bull. Johns Hopk. Hosp., 87, 186.

McDermott, E. N. (1928). Quart. J. Med., 21, 433.

Moore, J. E. (1949). Amer. J. Syph., 33, 43.

—_, Farmer, T. W., and Hoekenga, M. T. (1948). Trans. Ass. Amer. Phys., 61, 176.

Morrison, J. L., Heyman, A., and Sheldon, W. H. (1948). Unpublished data.

Nelson, R. A., and Mayer, M. M. (1949). J. exp. Med., 89, 369.

Porter, R. R. (1948). Va. med. Mon., 75, 357.

Rich, A. R. (1944). "Pathogenesis of Tuberculosis". Thomas, Springfield, Illinois.
Scott, V., Maxwell, R. W., and Skinner, J. S. (1949). J. Amer. med. Ass., 139, 217.

Shaffer, B., and Shenkin, H. A. (1950). Amer. J. Syph., 34, 78.

Sheldon, W. H., Cummings, M. M., and Evans, L. D. (1950). Proc. Soc. exp. Biol., N.Y., 75, 616.

(19), and Heyman, A. (1949). Amer. J. Syph., 33, 213.

_-, , and Evans, L. D. (1951a). Ibid., 35, 411.

,,$---(1951 \mathrm{~b})$. Ibid., 35, 405.

Sinclaire, H. A., and Webster, B. (1951). Ibid., 35, 312.

Stewart, J. J. (1949). Arch. Derm. Syph., Chicago, $60,427$.

Suchett-Kaye, A. I. (1951). Lancet, 1, 90.

Tucker, H. A., and Farmer, T. W. (1947). Arch. intern. Med., 80, 322.

Wheeler, C. E., and Curtis, A. C. (1951). Amer. J. Syph., 35, 319.

Whorton, C. M., and Denham, S. W. (1951). Ibid., 35, 255.

Williams, R. H. (1941). Arch. intern. Med., 68, 80.

Wolff, B. P. (1946). Ann. intern. Med., 24, 203.

Womack, C. R., and Wells, E. B. (1949). Amer. J. Med., 6, 267. 